\title{
CORRELATION OF SALIVARY AND PLASMATIC BUSULFAN CONCENTRATIONS: IMPLICATIONS FOR THERAPEUTIC MONITORING AND ORAL CRYOTHERAPY PROTOCOLS
}

\author{
F.P. Eduardo ${ }^{1}$, L.M. Bezinelli ${ }^{1}$, M.H. Ferreira ${ }^{2}$, D.L.C. Carvalho², F.C.P. Rosin' ${ }^{1}$, C.E.D.S. Ferreira ${ }^{1}$, N. Hamerschlak ${ }^{1}$, L.
} Correa ${ }^{2}$.

${ }^{1}$ Hospital Israelita Albert Einstein, Hematology, Sao Paulo, Brazil.

${ }^{2}$ School of Dentistry- University of São Paulo, General Pathology Department, Sao Paulo, Brazil.

\section{INTRODUTION}

Individual dose adjustment of endovenous busulfan during conditioning of hematopoietic cell transplantation (HCT) reduces the toxicity and improves the therapeutic outcomes of this drug. Busulfan therapeutic monitoring demands multiple blood collections for measurement of its plasmatic concentration, which can provoke discomfort to the patients. This agent is found in the saliva during the conditioning, but its salivary pharmacokinetics is unknown

\section{OBJETIVES}

$\checkmark$ Compare the busulfan concentration in saliva and plasma during the $\mathrm{HCT}$ conditioning, analyzing the viability for future busulfan therapeutic monitoring using saliva.

$\checkmark$ Propose an oral cryotherapy protocol for reducing the toxicity in the oral cavity, based on the salivary busulfan concentration curve.

\section{MATERIAL AND METHOD}

We collected saliva and blood from 20 patients undergoing allogeneic HCT. Blood and saliva samples were collected the time of baseline and 30,60, $120,180,240,300,360,420$ and 480 minutes after the first infusion. The initial standard dose of busulfan was $130 \mathrm{mg} / \mathrm{m} 2$. Busulfan was measured in saliva and plasma using a previous standardized and validated ultra highperformance liquid chromatography method.

After analysis of the plasma busulfan, the dose was then adjusted, continuing the conditioning, which occurred with a daily dose adjusted for another 2 days. Some patients then performed more than one quantification, done on different days. In total, 32 analyzes of each collection time were included, totalizing 320 measures.
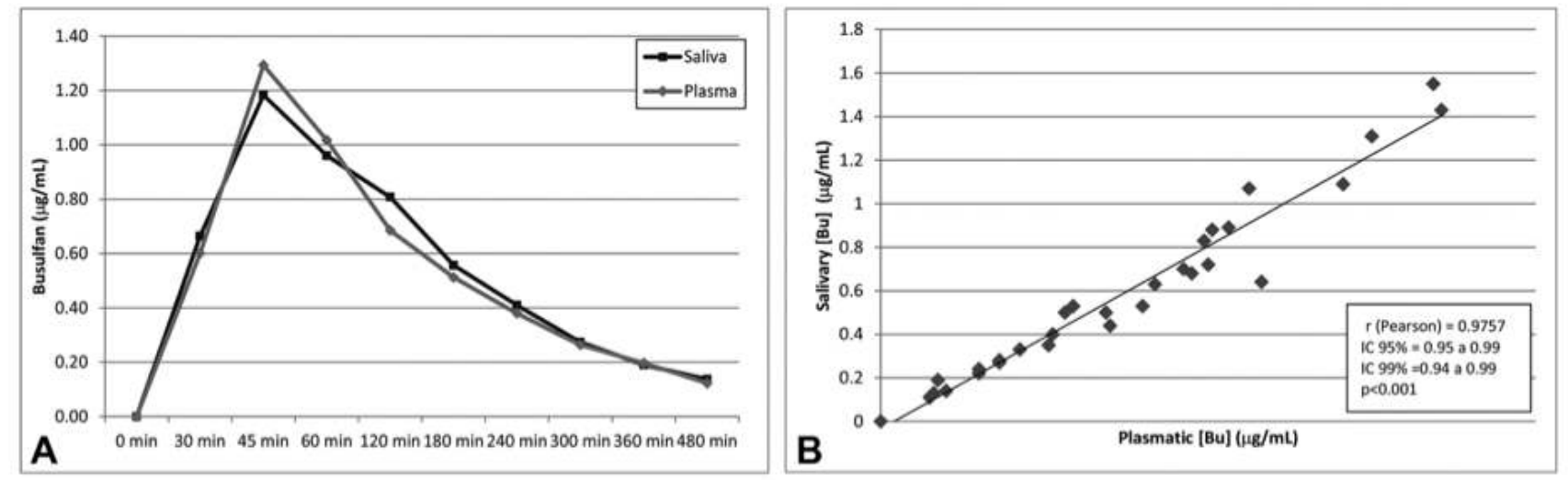

Figure 1 - A: Curve of busulfan concentration detected in plasma and saliva B: Correlation between plasmatic and salivary busulfan concentrations.

\section{STATISTICAL ANALYSIS}

The values were showed in mean and standard-deviation. Salivary and plasmatic Bu concentrations were compared by $\mathrm{t}$ paired statistical test. Correlation between the two concentrations was analyzed by Pearson correlation test. The level of significant was $5 \%$.

RESULTS

The quantification of busulfan in saliva showed a high correlation with plasma $(r=0.92, \mathrm{Cl}-0.89-0.93, p<0.001)$ (Figure 1A), with similar curves between them (Figure 1B).

We found a significant high correlation between plasmatic and salivary busulfan concentrations $(r=0.92, \mathrm{Cl}-$ $0.89-0.93, p<0.001$ ). The drug peak in the both fluids was at $180 \mathrm{~min}$, decreasing to the half of the peak concentration at $300 \mathrm{~min}$; however, after $480 \mathrm{~min}$, time of the last collection, there was no return to zero values. Considering the similarities between the concentrations values found in plasma and saliva, the oral mucosa is exposed to a double source of toxicity. For an efficient oral cryotherapy protocol, the procedure should initiate after 120 min of the busulfan infusion and extent at least $360 \mathrm{~min}$.

\section{CONCLUSION}

In conclusion, the saliva is a good alternative matrix for busulfan therapeutic monitoring. The agreement between the salivary and plasmatic concentration curves encourage an adoption of oral cryotherapy for minimize the toxic effects of busulfan in the oral cavity.

We thank the São Paulo Research Foundation (FAPESP, Proc. \# 2016/03650-4) and AmigoH for their financial support

Rauh M, Stachel D, Kuhlen M, Gröschl M, Holter W, Rascher W. Quantification of busulfan insaliva and plasma in haematopoietic stem cell transplantation in children : validation of liquid chromatography tandem mass spectrometry method. Clin Pharmacokinet. 2006;45(3):305-16. Mauramo M, Rohde L, Ramseier AM, Rovó A, Waltimo T. Determinants of stimulated salivary flow among haematopoietic stem cell transplantation recipients. Clin Oral Investig. 2016. Ciurea SO, Andersson BS. Busulfan in hematopoietic stem cell transplantation. Biol Blood Marrow Transplant. 2009 May,15(5).523-36. Bezinelli LM, Eduardo FP, de Carvalho DLC, Dos Santos Ferreira CE, de Almeida EV, Sanches LR, Esteves I, Campregher PV, Hame Transplant. 2017 Oct:52(10):1384-1389. doi: 10.1038/bmt2017.142. Epub $2017 \mathrm{Jul} 24$. 